\title{
Brote de influenza A (H1N1) humano en pavos en un criadero comercial, Valparaíso, Chile. 2009
}

\author{
Elena Pedroni, Ximena Muñoz, Viviana Sotomayor, Juan C. Muñoz, \\ Myriam Arenas, Rodrigo Fasce y Andrea Olea
}

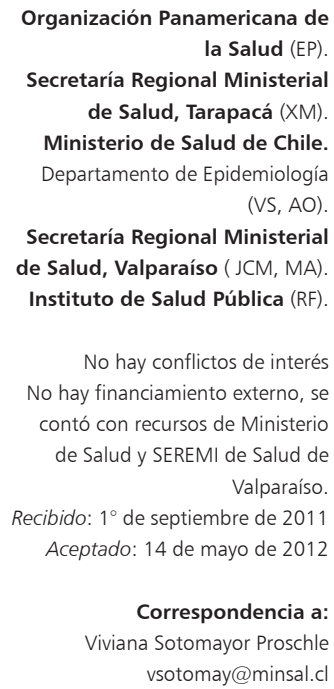

No hay conflictos de interés No hay financiamiento externo, se contó con recursos de Ministerio de Salud y SEREMI de Salud de Valparaíso.

Recibido: $1^{\circ}$ de septiembre de 2011 Aceptado: 14 de mayo de 2012

Correspondencia a: Viviana Sotomayor Proschle vsotomay@minsal.c

\section{Outbreak of human A (H1N1) influenza in turkeys of a commercial poultry farm,} Valparaiso, Chile. August 2009

The Chilean Ministry of Health (MINSAL) led an investigation to identify associated factors to human influenza A (H1N1) infection in turkeys from poultry farms, Valparaíso. The Agriculture and Livestock Farming Service (SAG) informed the detection of influenza A (low pathogenicity) in turkeys and the Public Health Institute (ISP) confirmed influenza A (H1N1).The study included $100 \%$ of operative wards: $31 \%$ presented positive event (influenza A (H1N1)); 60\% if considered only reproductive wards. Dissemination and dispersion velocity of 13 wards in 18 days evidenced a continuous common source. Interviews were performed to $89 \%$ of workers of whom $20 \%$ presented influenza-like disease: $26 \%$ from reproductive wards and $4 \%$ from raising and rearing farms. Of 15 risk factors studied insemination and age in females showed statistically significant RR in low oviposition index wards. A man-bird transmission is proposed, through direct transmission of saliva during manual insemination or indirect transmission through contaminated semen. To the authors, this is the first turkey 2009 influenza H1N1 outbreak detected worldwide,in this case with a documented cloacal transmission path.

Key words: Influenza, human, influenza in birds, influenza A virus, H1N1 subtype, aviculture.

Palabras clave: Gripe humana, subtipo H1N1 del virus de la influenza A, avícolas, gripe aviar.

\section{Introducción}

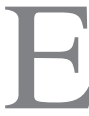
n Chile, el único brote reconocido de influenza aviar ocurrió en mayo 2002, en una planta avícola en una localidad rural de San Antonio, Región de Valparaíso. Fue causado por virus H7N3 de alta patogenicidad y erradicado exitosamente mediante el sacrificio de 500.000 aves (pollos y pavos), el aislamiento geográfico del área, el uso de mallas repelentes para roedores y aves silvestres, entre otras medidas ${ }^{1,2}$. En ese brote no se detectaron casos humanos (Bodor P, Sotomayor V, Fasce R, González G, Cid A, et al. Estudio serológico de influenza aviar en trabajadores expuestos a influenza aviar, brote 2002. Fuente: Resumen trabajo Curso de Investigación y Control de Brotes Epidémicos. Ministerio de Salud Chile, 2004. (Datos no publicados).

El 13 de agosto de 2009, semana epidemiológica (SE) 32, el Servicio Agrícola Ganadero (SAG) recibió una denuncia de caída brusca de postura iniciada a fines de julio en lotes en producción de reproductoras de pavos en dos granjas (LPA y PUCR) de una empresa avícola comercial, ubicadas en las comunas de Quilpué y Nogales, respectivamente (distantes 43 km una de otra), Región de Valparaíso. Las aves no presentaron sintomatología respiratoria y tampoco se detectó aumento de la mortalidad ni lesiones macroscópicas compatibles con un cuadro de influenza aviar ${ }^{3}$.
El 18 de agosto de 2009 (SE 33), el SAG informó al Ministerio de Salud (MINSAL) acerca de la detección del virus influenza A de baja patogenicidad en los sectores afectados de Valparaíso ${ }^{4}$. Hasta esa fecha, la región registraba un acumulado de 42.407 notificaciones de casos sospechosos de influenza $\mathrm{A}(\mathrm{H} 1 \mathrm{~N} 1)$, con un máximo en la SE $28^{5}$.

El 27 de agosto el Instituto de Salud Pública (ISP) confirmó mediante la técnica de RPC-TR, que se trataba del virus influenza A(H1N1). Paralelamente, el 26 de agosto el MINSAL emitió una alerta a las autoridades sanitarias regionales con el objetivo de fortalecer la vigilancia de enfermedad respiratoria y reforzar las acciones de prevención y control en trabajadores de plantas avícolas, según la normativa de influenza pandémica e influenza aviar ${ }^{6,7}$.

Una vez conocido el evento, el SAG investigó en terreno obteniendo los siguientes resultados e hipótesis:

- Las necropsias a las aves afectadas dieron cuenta de lesiones del tracto reproductivo, como salpingoperitonitis y salpingitis.

- La infección estuvo concentrada en las aves reproductoras de las granjas LPA y PUCR y no se diseminó a otros estratos productivos (Cría y Recría).

- El inicio de la infección habría ocurrido entre el 15 y 22 de julio, planteándose como hipótesis la exposición de las aves a un ser humano infectado y transmisor del virus o por aves silvestres infectadas (virus aviar). 
- Posiblemente la difusión entre las granjas se podía relacionar con el movimiento de personas y vehículos entre las mismas.

Frente a la evidencia de traspaso de virus entre especies, a la presencia de virus pandémico A(H1N1) y al desconocimiento del riesgo potencial para la salud humana y animal, el MINSAL decidió llevar a cabo una investigación con la cooperación de la empresa avícola afectada, el SAG y la Organización Panamericana de la Salud (OPS).

El objetivo fue identificar la fuente de transmisión y los factores de exposición asociados con el estado de infección por influenza A(H1N1) humana en los pavos de las granjas LPA y PUCR.

\section{Material y Método}

El período de estudio estuvo comprendido entre el 1 de julio (25 días antes de la fecha de detección de la caída de la postura) y el 9 de septiembre (fecha de finalización de las entrevistas).

Se realizó un estudio analítico de cohorte retrospectiva tomando como sujeto de estudio los pabellones para identificar la fuente de transmisión y los factores de exposición asociados con el estado de infección de los pavos.

El universo estuvo representado por las granjas productoras de pavos de la empresa avícola afectada en sus distintas etapas de producción (cría, recría y reproducción) ubicadas en las comunas de Nogales y Quilpué, Región de Valparaíso: en total 4 granjas (PUCC de cría, LEO de recría y las reproductoras LPA y PUCR), 24 sectores y 85 pabellones.

Como evento positivo se consideró todo pabellón que presentara uno o más pavos con muestra positiva para influenza H1N1 2009 en el período de estudio. Por las observaciones e hipótesis realizadas por el SAG, se incluyeron en el análisis de los factores de riesgo las variables de sexo y edad de las aves, y las actividades que los trabajadores realizaron en cada uno de los pabellones entre 15 a 25 días antes de la detección de la baja en la ovipostura: alimentación, barrido, remoción de camas, vacunación, extracción de semen, inseminación manual, inseminación mecánica, pillaje, recogida de huevos, tacto, despique. Se midió ausencia o presencia de estas actividades en pabellones con y sin evento y se calculó el riesgo relativo $(\mathrm{RR})$.

Se entrevistaron informantes claves: directivos de la empresa, veterinario de las granjas, personal del SAG, personal de salud que atendió a trabajadores de las granjas. Se entrevistó además a los trabajadores (106 en total: 77 de carácter permanente y 29 contratistas de un empresa externa) que realizaron actividades en las granjas entre el $1^{\mathrm{o}}$ de julio y el 14 de agosto (fecha en que se adoptaron las nuevas medidas de bioseguridad).

Se utilizaron dos cuestionarios diseñados para tal fin: uno semi estructurado que recogió información de la persona y sus antecedentes clínicos y epidemiológicos para identificar casos de enfermedad tipo influenza (ETI) según la definición oficial del MINSAL ${ }^{6}$; el otro correspondió a un cuestionario con preguntas abiertas sobre las actividades que los trabajadores realizaron dentro de la granja en el período de estudio y la forma en que se realizaron éstas, así como las medidas de bioseguridad adoptadas.

También se realizó una observación directa de simulaciones de las prácticas relacionadas con las hipótesis; es decir, se pidió a los trabajadores entrevistados que describieran y representaran las actividades de pillaje, extracción de semen e inseminación.

Se conformaron dos grupos para el trabajo de campo: cada grupo contó con un personal de enfermería para la extracción de sangre y dos encuestadores (epidemiólogos).

A las muestras se les realizó determinación de títulos de anticuerpos anti influenza $\mathrm{A}(\mathrm{H} 1 \mathrm{~N} 1)$ pandémica mediante técnica de inhibición de la hemaglutinación (IHA), de acuerdo a la metodología estandarizada y difundida a los centros nacionales de influenza por el Centro de Control de Enfermedades y Prevención de Estados Unidos (CDC). Para la hemaglutinación se utilizaron eritrocitos de pavo a una concentración final de $0,5 \%$. Como controles se usaron una cepa de antígeno de control A(H1N1) pandémica y un antisuero de referencia para $\mathrm{A}(\mathrm{H} 1 \mathrm{~N} 1)$ pandémica entregados por el CDC. El ensayo se realizó para cada una de las muestras desde una dilución inicial de 1:10 a una dilución final de 1:1.280. Fueron considerados como positivos aquellas muestras con títulos de anticuerpos mayores o iguales a 1:40. En esta publicación no se incluyen los resultados de este análisis, los que serán publicados a futuro.

Los vehículos utilizados para el traslado del equipo de investigadores fueron desinfectados en rodiluvio y ducha sanitaria. El equipo investigador fue provisto de ropa desechable por la empresa avícola.

Análisis estadístico: Se utilizó Epi info 6 para el cálculo del riesgo relativo crudo y para los ajustes correspondientes a través de estratificación según riesgo.

\section{Resultados}

Cobertura del estudio. La investigación incluyó las cuatro granjas y 77 pabellones de los 85 (8 pabellones se encontraban vacíos en el período de estudio): 16 de cría, 21 de recría y 40 de reproducción, con una cobertura de $100 \%$ de los pabellones operativos.

Se entrevistó a 94 trabajadores (88,7\%). Todos los trabajadores entrevistados fueron varones, con una mediana de edad de 37 años (rango 19 a 73 años). El 73,4\% (69/94) 
trabajó en las granjas de reproducción durante el período de estudio y el resto, en las granjas de cría y recría.

Descripción de las granjas y actividades regulares. Durante el período de estudio, en las granjas se realizaban actividades asociadas a las tres etapas de producción (Figura 1):

- Etapa Cría: realizada en la granja PUCC crianza, con cuatro sectores y 16 pabellones. Las principales actividades realizadas en esta etapa eran: alimentación, regulación de iluminación, control de temperatura ambiental, lavado de bebederos, movimiento de cama, control de mortalidad y necropsia de aves.

- Etapa Recría: realizada en la granja LEO, con siete sectores y 21 pabellones. Las principales actividades realizadas eran: alimentación, regulación de iluminación, control de temperatura ambiental, lavado de bebederos, movimiento de cama, pillaje, estimulación de machos, vacunación, desparasitación, necropsia de aves, barrido en pabellones de machos, despique, control de mortalidad y necropsia de aves.

- Etapa Reproducción (postura de huevos): realizada en las granjas LPA reproducción (siete sectores y 21 pabellones operativos) y PUCC reproducción (seis sectores y 19 pabellones operativos). Las principales actividades eran: las actividades regulares de alimentación, movimiento de cama, barrido de pasillo, pillaje, se suman la apertura de nidos en la mañana y cierre en la tarde, colecta de huevos en el nido y en el piso, tacto cloacal, separación de cluecas, estimulación de machos, extracción de semen, inseminación manual y mecánica a las hembras. También se realizaba el control de mortalidad y necropsia de aves.
Esta etapa se subdividía en primer ciclo de ovipostura, pelecha y segundo ciclo de ovipostura. A la semana 32 comenzaba un período intensivo de estimulación para iniciar la postura. El proceso involucraba la realización de tres inseminaciones en un lapso de 8 días. Desde la semana 35 a 56 se consideraba la etapa de mayor producción de huevos ( $1^{\circ}$ ciclo de postura) con inseminación cada siete días aproximadamente, extrayendo el semen de los machos del mismo lote.

Luego comenzaba el período de pelecha, los machos se enviaban a faena y las hembras entraban en un período de muda forzada para estimular la producción de huevos.

Para el $2^{\circ}$ ciclo de postura, se comenzaba nuevamente la inseminación intensiva con machos jóvenes (tres veces en ocho días) y luego pasaban a régimen regular de una vez cada 7-9 días. Luego, todas las aves pasaban a faena.

La estimulación de machos y extracción de semen se realizaba entre cuatro trabajadores externos y el inseminador oficial o subrogante. Uno de los trabajadores externos estimulaba sexualmente al ave con la mano sin guante. Otro trabajador (generalmente el inseminador) obtenía el semen usando un tubo con dos salidas: en una insertaba la manguera de succión y en la otra se insertaba la manguera para aspirar el semen. El semen se vaciaba en un frasco donde se diluía y se aplicaba gentamicina como bactericida. Este semen se utilizaba en forma inmediata para la inseminación.

Para la estimulación e inseminación de hembras se utilizaban dos técnicas: manual y mecanizada.

- La inseminación manual se realizaba en hembras jóvenes y hembras post-pelecha. Se utilizaba una pipeta de vidrio de 0,2 cc conectada a una manguera ( 1 a 1,5
Figura 1. Distribución de pabellones con evento según fecha de inicio de la baja de ovispostura. Brote de influenza H1N1 en pavos, Valparaíso, Chile, 2009.
Refuerzo medidas de las medidas de bioseguridad

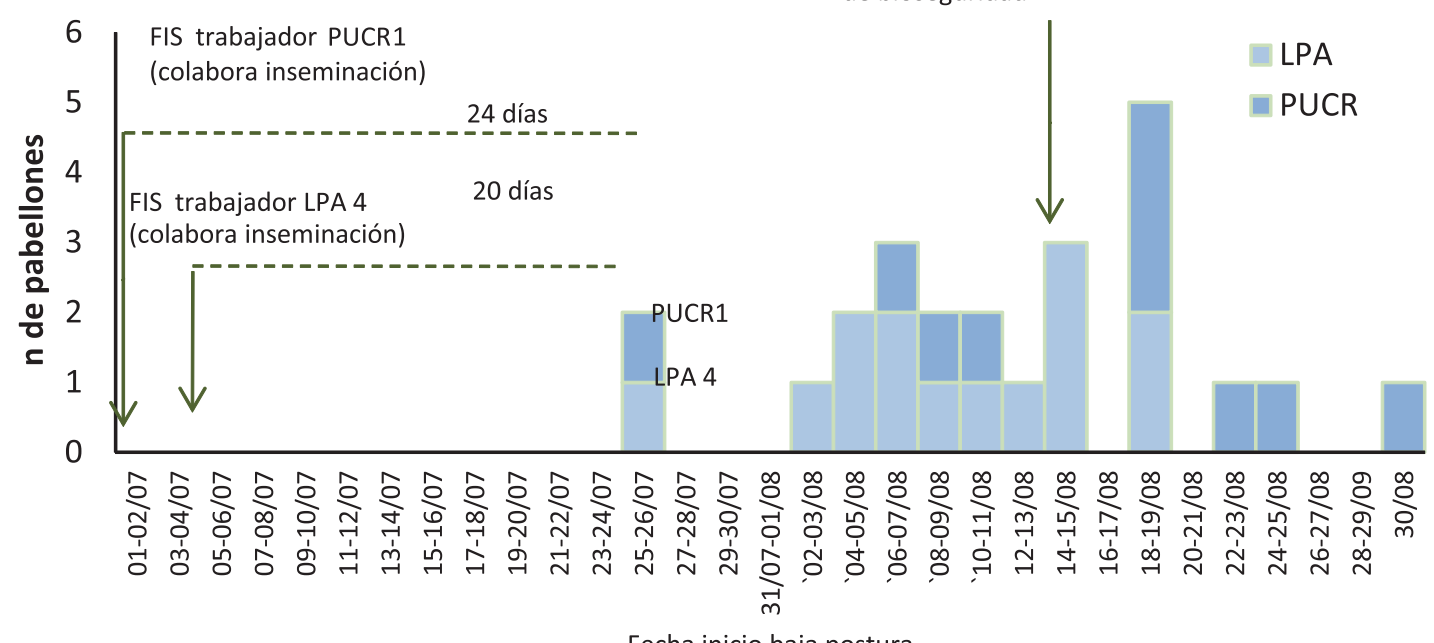

Fecha inicio baja postura 
metros) Tres pilladores tomaban una hembra cada uno y exponían la cloaca con la mano sin guante. El inseminador enrasaba la pipeta a 0,04 cc aproximadamente, con el semen contenido en un frasco que mantenía en una mano y empujaba mediante un soplido, a través de la manguera, el contenido dentro del órgano sexual de la hembra. Esta práctica se realizaba en todo el pabellón (1.000 a 1.500 hembras) con la misma pipeta y manguera, sin mediar procedimientos de esterilización entre las inseminaciones.

- La inseminación con máquina se realizaba en las hembras en postura con una pistola con pipetas individuales para cada ave. Se alternaban la práctica manual con la máquina, porque: (a) la manual es “más rápida”; (b) a veces utilizan durante la mañana la máquina y en la tarde la manual para “desocuparse más temprano y no volver a lavarla”; (c) las pipetas de las máquinas no se encuentran en condiciones de ser usada por deterioro que se produce durante el proceso de re esterilización (terminan utilizando la misma pipeta para varias pavas o cambian a la manual) y (d) las máquinas no siempre están disponible por mantenimiento o uso en otro sector.

Uso de medidas de bioseguridad antes de la confirmación del evento. Según el relato de los trabajadores, el uso de la mascarilla era poco frecuente $(6 \%)$, sólo para tareas que implicaban levantamiento de polvo. Durante la extracción de semen o inseminación manual, no se usaba, aunque dos de los inseminadores refirieron realizar un orificio en la mascarilla por donde pasa la manguera de succión e inoculación.

Todos los trabajadores usaron la ducha (100\%) en ese período, así como la ropa y calzado de trabajo que entregaba la empresa; $90 \%$ utilizó los pediluvios de cloro en polvo o desinfectante líquido y 63\% usó el alcohol gel en manos o sobre el guante de látex cuando hacían uso del mismo en la recolección de huevos; refirieron el uso de guantes de látex para las tareas de tacto (un par de guantes cada 400 hembras consecutivas, aproximadamente). Además, para las tareas pesadas (pillaje de aves, barrido, remover cama), utilizaban guantes de hilo para la protección de las manos, los que se renovaban cada 7 a 10 días. Este guante se usaba en una sola mano para el pillaje, ya que con la otra realizan la estimulación del macho y de la hembra a mano descubierta.

Dentro de un mismo sector, en los diferentes pabellones, se utilizaban los mismos elementos de trabajo (horqueta, escobas, guantes de hilo, baldes, etc.).

Los trabajadores señalaron el uso de fumigación a los elementos de trabajo, artefactos como incubadoras o maquina de inseminación, preparación de pabellones para el ingreso de nuevos lotes. Esta fumigación también se realizaba a los recipientes en los que los trabajadores llevaban su colación para la jornada de trabajo.
Manifestaciones clínicas de los trabajadores. Diecinueve de los 94 trabajadores (20\%) presentaron un cuadro de ETI. El 26\% (18/69) de los trabajadores de las granjas de reproducción se enfermó, mientras que esta proporción fue menor (1/25) entre los trabajadores de las granjas de cría y recría.

Diez de los 19 trabajadores enfermos acudieron a un establecimiento de salud y dos recibieron terapia con oseltamivir; a ninguno se le realizó prueba de laboratorio confirmatoria para virus respiratorios, uno de ellos fue hospitalizado y no se registraron fallecidos. Se otorgó licencia médica a seis trabajadores.

El 79\% (67/85) de los trabajadores refirió haber recibido la vacuna contra la influenza estacional durante ese año.

Se identificó un caso perteneciente al pabellón 4 de la granja reproductora LPA cuya fecha de inicio de síntomas (FIS) fue el 5 de julio de 2009, es decir, 20 días antes del inicio de la baja de postura en dicha granja. Asimismo, se identificó un caso del pabellón 1 de la granja reproductora PUCC, cuya FIS comenzó 24 días antes del inicio de la baja de la postura. Ambos trabajadores realizaron en ese período tareas relacionadas con la inseminación (Figura 1).

Descripción del evento. En el período de estudio se identificaron 24 pabellones con presencia del evento positivo (31\%) de los 77 pabellones estudiados, todos correspondientes a hembras. Si se considera sólo los pabellones para reproducción, el porcentaje se eleva a $60 \%(24 / 40)$ (Tabla 1).

Además de la baja en la ovipostura, 40,4\% (38/94) de los trabajadores manifestó también encontrar a las “aves inquietas, alteradas, asustadas, apagadas, ariscas, inapetentes, mayor consumo de agua, humedad excesiva en el piso de las cluequeras, contenido líquido y caliente al tacto cloacal, huevos deformes y blandos". No se registraron muertes en las aves durante el brote.

El evento se manifestó simultáneamente en los pabellones 4 de LPA (LPA4) y 1 de PUCR (PUCC1), los días 25 y 26 de julio. A los 8 días de iniciado en LPA comenzó la

\begin{tabular}{|c|c|c|c|c|c|c|c|}
\hline \multirow{3}{*}{$\begin{array}{l}\text { Nombre } \\
\text { de la } \\
\text { granja }\end{array}$} & \multirow{3}{*}{$\begin{array}{l}\text { Etapa de } \\
\text { producción }\end{array}$} & \multicolumn{3}{|c|}{ Pabellones operativos } & \multicolumn{3}{|c|}{ Trabajadores entrevistados } \\
\hline & & \multirow[t]{2}{*}{ Total } & \multicolumn{2}{|c|}{ Con eventos positivos } & \multirow[t]{2}{*}{ Total } & \multicolumn{2}{|c|}{ Casos de ETI } \\
\hline & & & $\mathbf{n}$ & $\%$ & & $\mathrm{n}$ & $\%$ \\
\hline PUCC & Cría & 16 & 0 & \multirow{2}{*}{0} & \multirow{2}{*}{25} & \multirow{2}{*}{1} & \multirow{2}{*}{4} \\
\hline LEO & Recría & 21 & 0 & & & & \\
\hline LPA & Reproducción & 20 & 14 & \multirow{2}{*}{60} & \multirow{2}{*}{69} & \multirow{2}{*}{18} & \multirow{2}{*}{26} \\
\hline PUCR & Reproducción & 20 & 10 & & & & \\
\hline Total & & 77 & 24 & 31 & 93 & 19 & 20 \\
\hline
\end{tabular}


Tabla 2. Frecuencia de factores de riesgo en pabellones. Brote de influenza H1N1 en pavos. Valparaíso, Chile, 2009

\begin{tabular}{|c|c|c|c|c|c|c|c|c|c|}
\hline \multirow[t]{2}{*}{ Factores de riesgo } & \multicolumn{3}{|c|}{ PAB con evento $(n=24)$} & \multicolumn{3}{|c|}{ PAB sin evento $(n=49)$} & \multirow[t]{2}{*}{ RR } & \multirow[t]{2}{*}{ IC (95\%) } & \multirow[t]{2}{*}{ p } \\
\hline & Sí & No & $\%$ & Sí & No & $\%$ & & & \\
\hline Inseminación manual & 14 & 10 & 58,3 & 3 & 46 & 6,1 & 4,61 & $2,52-4,49$ & $<0,001$ \\
\hline Inseminación máquina & 19 & 5 & 79,2 & 3 & 46 & 6,1 & 8,81 & $3,77-20,59$ & $<0,001$ \\
\hline Inseminación cualquiera & 22 & 2 & 91,7 & 3 & 46 & 6,1 & 21,12 & $5,40-82,65$ & $<0,001$ \\
\hline Edad 35-56 sem & 15 & 9 & 62,5 & 9 & 40 & 22,5 & 3,40 & $1,75-6,63$ & 0,004 \\
\hline Hembras $35-56$ sem & 15 & 9 & 62,5 & 2 & 47 & 4,3 & 5,49 & $2,94-10,24$ & $<0,001$ \\
\hline
\end{tabular}

diseminación en el resto de los pabellones, y a los 12 días en PUCC. El último pabellón en presentar el evento, lo hizo el 30 de agosto en la granja PUCC. La curva muestra una fuente común continua, con una mayor diseminación y velocidad en la granja LPA con 13 pabellones afectados en 18 días (Figura 1). El 14 de agosto, la empresa avícola reforzó las nuevas medidas de bioseguridad.

Teniendo en cuenta el período de transmisibilidad de la influenza desde un día antes de iniciar síntomas y hasta cinco días después, se puede estimar que el período entre el inicio de la infección y el alerta de baja de ovipostura fue de 15 a 25 días (Figura 1).

Factores de riesgo o exposición. De los 15 factores de riesgo analizados, la inseminación (manual, mecánica o ambas) y la edad de las hembras mostraron riesgos relativos (RR) superiores y estadísticamente significativos en los planteles con baja de ovipostura (Tabla 2).

Ajustando los dos estratos (hembras de 35-56 semanas versus el resto de las hembras) según el factor de riesgo “inseminación cualquiera”, el RR ajustado de ambas variables disminuyen a [1,29 (0,92-1,80); $\mathrm{p}=0,145]$ y [1,35 (1,01-1,82); $\mathrm{p}=0,05]$, respectivamente.

\section{Discusión}

En las granjas de pavos de la empresa avícola comercial de Valparaíso se registró un brote de influenza humana A(H1N1) 2009, a partir del 25 de julio, que afectó a 60\% de los pabellones de hembras en etapa de reproducción. El mismo comenzó en forma simultánea en dos granjas ubicadas a $43 \mathrm{~km}$ de distancia y se produjo en el momento de mayor notificación de casos de enfermedad respiratoria en la Región de Valparaíso, identificando trabajadores con ETI desempeñando sus actividades en período de transmisibilidad de la enfermedad.

Las manifestaciones encontradas en las aves no fueron de tipo respiratoria como se esperaría según lo reportado en la literatura científica para los virus de influenza aviar.
La anatomía patológica de las aves afectadas sólo mostró lesiones del tracto reproductivo como salpingo-peritonitis y salpingitis. La manifestación en la baja de la ovipostura es compatible con la descrita en la literatura científica para este tipo de aves, ya que en los pavos, con infecciones de virus de influenza de baja patogenicidad, el principal síntoma es la disminución en la producción de huevos ${ }^{8,9}$. Los machos no se vieron afectados a pesar que los mismos trabajadores enfermos realizaron tareas en sus pabellones y en la misma época.

Probablemente la infección humano-ave se produjo tres semanas antes del inicio de la baja de la ovipostura, coincidente con la presencia de enfermedad respiratoria en trabajadores de los dos primeros pabellones de dos granjas de reproductoras afectados y que laboraban en dicha fecha en tareas de inseminación. Dos semanas después del inicio de la baja de la ovipostura, comienza a manifestarse el mismo evento en otros pabellones, siendo de mayor magnitud y velocidad de diseminación en la granja LPA, y mostrando un modo de transmisión compatible con una fuente común continua.

El estudio mostró que las actividades de inseminación, tanto manual como automática, aumenta el riesgo de que el pabellón presente el evento. La probabilidad de que la edad de máxima reproducción de las aves aumente el riesgo de enfermar se descartó, al ajustarlo según el factor inseminación. Con estos hallazgos se plantean dos posibilidades de transmisión hombre-ave: (i) transmisión directa por saliva o secreción respiratoria a través de la manguera de la inseminación manual o; (ii) transmisión indirecta a través de semen contaminado por saliva o secreción respiratoria del trabajador, que en el momento del estudio no pudo analizarse por laboratorio ya que se prepara e inocula en el momento de la inseminación.

Estos resultados, sumados a la descripción de la operatividad de las prácticas, el mal uso de las medidas de bioseguridad, las manifestaciones presentadas por las aves, los resultados de la anatomía patológica, y el modo de transmisión expresado por la curva, mostrarían que la fuente de infección fue el hombre, que la puerta 
de entrada probablemente fue la cloaca y que se produjo a través de las prácticas de inseminación. Esta práctica, sumada a las tareas de tacto cloacal utilizando el mismo guante, tuvo un rol importante en la diseminación. Estos hallazgos coinciden con lo descrito por otros autores en un estudio de virus influenza A(H3N2) triple reagrupado en pavos de reproducción y sus potenciales repercusiones para los estudios de vacunas en los pavos ${ }^{10}$.

Éste, fue el primer brote de influenza H1N1 2009 en pavos, detectado en el mundo y en el que se comprueba la vía de transmisión cloacal.

La empresa contaba con medidas para prevenir o impedir el ingreso y salida de agentes infecciosos a los planteles avícolas según normas nacionales e internacionales. La contención del virus en las granjas positivas (LAP y PUCR) se realizó también adecuadamente según las pautas recomendadas por el SAG ${ }^{11}$.

En esta oportunidad, el virus se comportó como de baja patogenicidad, siendo importante extremar las medidas de bioseguridad para contribuir a evitar posibles co-infecciones y futuras mutaciones. El mejoramiento de las prácticas de inseminación manual, extracción y preparación del semen y el tacto cloacal, contribuirán a evitar brotes de estas características.

El sistema de vigilancia de eventos inusitados relacionados con enfermedades respiratorias agudas, en este caso específico, enfermedad en aves y en trabajadores relacionados con aves, debe fortalecerse de modo de mejorar la oportunidad de detección, investigación y control. Por otra parte, las medidas de prevención en los trabajadores agrícolas deben incluir además de las medidas de bioseguridad, la vacunación contra la influenza, la que de acuerdo a las recomendaciones de los grupos de expertos internacionales debe mantenerse en esta población de riesgo ${ }^{12,13}$.

Agradecimientos. Al equipo de la Seremi de Salud de Valparaíso: Leonor Rivas, Constanza Harbin, Paulina Tapia, M. Angélica Trincado que participaron en la investigación. A Carlos Pavletic y Sandra Poblete de la División de Políticas Pública del MINSAL; Álvaro González del Servicio Agrícola Ganadero, a los encargados de la Empresa e Instituto de Seguridad del Trabajador por las actividades de coordinación y facilidades para realizar la investigación y finalmente a Eduardo Álvarez de OPS-Chile por su apoyo en la investigación de este evento.

\section{Resumen}

El MINSAL lideró una investigación para identificar factores asociados a infección por influenza A(H1N1) en pavos de planteles avícolas, Valparaíso. El Servicio Agrícola Ganadero informó la detección de influenza A (baja patogenicidad) en pavos y el ISP confirmó influenza A(H1N1). El estudio incluyó 100\% de los pabellones operativos: $31 \%$ presentó evento positivo (influenza A(H1N1); 60\% al considerar sólo pabellones de reproducción. La diseminación y velocidad de dispersión de 13 pabellones en 18 días evidenció una fuente común continua. Se entrevistó a $89 \%$ de los trabajadores y $20 \%$ presentó ETI: 26\% de pabellones de reproducción y 4\% de granjas de cría y recría. De 15 factores analizados, inseminación y edad de las hembras mostraron RR estadísticamente significativos en los planteles con baja ovipostura. Se plantea transmisión hombre-ave directa por saliva en inseminación manual o transmisión indirecta por semen contaminado. Es el primer brote de influenza A(H1N1) 2009 en pavos detectado en el mundo y que se comprueba vía de transmisión cloacal.

\section{Referencias bibliográficas}

1.- Rojas H, Moreira R, Avalos P, Capua I, Marangon S. Avian influenza in poultry in Chile. Vet Rec 2002; 151: 88.

2.- Suárez D, Senne D, Banks J, Brown I, Essen S, Won Lee Ch, et al. Recombination resulting in virulence shift in avian influenza outbreak, Chile. Emerg Infect Dis 2004; 10 (4): 693-9.

3.- Mathieu C, Moreno V, Retamal P, González A, Rivera A, Fuller J, et al. Pandemic (H1N1) 2009 in breeding turkeys, Valparaiso, Chile. Emerg Infect Dis 2010; 16 (4): 709-11.

4.- Servicio Agrícola y Ganadero, Subdepartamento de Vigilancia Epidemiológica. Informe Epidemiológico preliminar: Detección de influenza aviar en aves reproductoras de pavos, Comunas de Nogales y Quilpue, Región de Valparaíso, 20 de agosto de 2009; 18: 53 horas.
5.- Ministerio de Salud de Chile: Influenza pandémica (H1N1) 2009. Reporte Situación 2009, 24 de Julio de 2009. Disponible en http://www.pandemia.cl/templates/pandemia/ documentos/Informe_24_julio.pdf. (accedido 2 de agosto de 2011).

6.- Ministerio de Salud de Chile. Departamento de Epidemiología Circular "Vigilancia de la Nueva Influenza Humana A (H1N1) Circular/N ${ }^{\circ}$ B 51/ 24 del 19 de junio 2009, disponible http://www. pandemia.cl/templates/pandemia/documentos/ prensa/reporte_24_07_09.pdf . (accedido 2 de agosto de 2011).

7.- Ministerio de Salud de Chile. Departamento de Epidemiología Circular de Vigilancia y Control de Influenza Aviar Circular N ${ }^{\circ}$ B51/ 2 de 19 de enero de 2007, disponible en http://www. pandemia.cl/templates/pandemia/documentos/ normativas_nacionales/circular_infl_aviar.pdf (accedido 2 de agosto de 2011).
8.- Suárez D L, Woolcock P R, Bermudez A J, Senne DA. Isolation from turkey breeder hens of a reassortant H1N2 influenza virus with swine, human, and avian lineage genes. Southeast Poultry Research Laboratory, Athens, GA 30605, USA. Avian Dis 2002; 46 (1): 111-21.

9.- Yu H, Zhang P C, Zhou Y J, Li G X, Pan J, Yan L P, et al. Isolation and genetic characterization of avian-like H1N1 and novel reassortant H1N2 influenza viruses from pigs in China. Division of Swine Infectious Diseases, Shanghai Veterinary Research Institute, Chinese Academy of Agricultural Sci-ences, No. 518, Ziyue Road, Minhang District, Shanghai 200241, China. Biochem Biophysic Res Commun 2009; 386 (2): 278-83.

10.- Pillai S P S, Pantin-Jackwood M, Jadhao S J, Suárez D L, Wang L, Yassine H M, et al. Pathobiology of triple reassortant H3N2 
influenza viruses in breeder tukeys and its potential implication for vaccine studies in turkeys. Vaccine 2009; 27: 819-24.

11.- Servicio Agrícola y Ganadero, Programa de Vigilancia Epidemiológica. Manual de procedimiento $\mathrm{N}^{\circ} 4$ BIOSAV/MP4,

Bioseguridad en plantas de incubación para las aves de carne y ponedoras de huevos comerciales. Disponible en www. sag.gov.cl http://www.sag.cl/common/asp/ pagAtachadorVisualizador.asp?argCrypted Data=GP1TkTXdhRJAS2Wp3v88hL8O1 mtiTZ16\&argModo $=$ \&argOrigen $=$ BD\&argFlagYaGrabados=\&argArchivoId= 3346.

12.- Lisa J, Delaney M S. NIOSH. Avian Influenza
Update: Worker Health and Safety. http://www. cdc.gov/flu/pp/worker_health_safety_11_2004. pdf

13.- Strategic Advisory Group of Experts: recommendations on the use of licensed human H5N1 influenza vaccines in the interpandemic period. Wkly Epidemiol Rec 2009; (84) 12 june; 244-8. 